\title{
Probing free volume property of polyamide thin film composites with different cross-linking densities
}

\begin{abstract}
Two commercial polyamide thin film composites (labelled AG and AK) with different polyamide (PA) cross-linking densities were examined for morphology, chemical structure, Doppler broadening positron annihilation spectroscopy, and salt desalination performance. The highly cross-linked AG sample resulted in higher salt rejection but slightly lower water permeance. Meanwhile the highly cross-linked sample showed smaller S parameters than the loosely cross-linked one. The highly cross-linked PA structure resulted in a higher salt rejection and lower water permeation rate. The free volume behavior resulting from various cross-linking densities is captured using the Doppler broadening annihilation spectroscopy.
\end{abstract}

Keywords: polyamide, cross-linking, thin-film composite, reverse-osmosis membranes, salt rejection, desalination

\author{
Volume 2 Issue I - 2018 \\ Ling Yung Hung,' Chien Chieh Hu, ${ }^{2}$ Wei Song \\ Hung, ${ }^{2}$ Shingjiang Jessie Lue $\mathrm{Lu}^{1,3,4}$ \\ 'Department of Chemical and Materials Engineering, Chang \\ Gung University, Taiwan \\ ${ }^{2}$ R\&D Center for Membrane Technology, Department of \\ Chemical Engineering, Chung Yuan University, Taiwan \\ ${ }^{3}$ Department of Radiation Oncology, Chang Gung Memorial \\ Hospital,Taiwan \\ ${ }^{4}$ Department of Safety, Health and Environmental Engineering, \\ Ming-Chi University of Technology, Taiwan
}

\author{
Correspondence: Shingiang Jessie Lue, Department of \\ Chemical and Materials Engineering, Chang Gung University, 259 \\ Wen-Hua First Road, Guishan District, Yaoyuan City, Taiwan 333, \\ Tel +88632I I8800, ext. 5489, Fax +88632II8700, \\ Email jessie@mail.cgu.edu.tw
}

Received: October 27, 2017 | Published: January 03, 2018
Abbreviations: RO, reverse osmosis; PA, polyamide; PSf, polysulfone; DBES, doppler broadening energy spectroscopy; FTIR, fourier transform infrared spectroscopy; ATR, attenuated total reflective

\section{Introduction}

Reverse osmosis (RO) membranes are commonly used for sea water desalination to produce fresh water. These membranes are usually prepared using interfacial polymerization. Hydrophobic diamine and water-soluble chloride salt precursor are reacted to form a thin polyamide (PA) separation layer on a porous support. ${ }^{1}$ The PA cross-linking density has a governing effect on the desalination performance of the resulting products.

These delicate PA top layers are less than one micrometer thick, and need to be characterized in order to tailor the material synthesis process. Doppler broadening positron annihilation spectroscopy has been proven to be a useful tool for probing the free volume property along the trans-membrane direction. ${ }^{2}$ By varying the incident beam energy into specimen, the depth profile of the free volume trait can be obtained.

Two commercial PA thin film composites are tested in this work, and their chemical structure, salt desalination efficiency, water permeance, and the associated Doppler broadening positron annihilation spectroscopy are evaluated. The desalination efficiency is discussed from the chemical structure view point, and supported by the Doppler broadening positron annihilation spectroscopy data.

\section{Materials and methods}

\section{Material characterization}

Two commercial RO membranes (AG and AK models) were purchased from GE Osmosis, Trevose, PA, USA. These membranes have a three-layer structure: polyamide top layer, intermediate layer of polysulfone (PSf), and non-woven support. The membrane morphology was investigated using field-emission scanning electron microscope (S-4800, Hitachi Ltd., Tokyo, Japan). Membrane samples were analyzed for chemical structure on attenuated total reflective Fourier transform infrared spectroscopy (ATR-FTIR, Perkin Elmer Spectrum One, Waltham, MA, USA) and x-ray photoelectron spectroscopy (XPS, Perkin Elmer Phi 1600 ESCA System, Waltham, MA, USA). Doppler broadening energy spectroscopy (DBES) was used to analyze the free volume properties of the PA thin films. ${ }^{2,3}$

\section{Desalination efficiency}

An RO system used in this study consisted of a feed tank, a pump (2SF35SEEL, Cat Pumps, Minneapolis, MN, USA, controlled by a frequency converter), a flat-sheet membrane module, and a permeate tank. A water bath and a heat exchanger were used to control the fluid temperature. The studied RO membrane had a $0.014 \mathrm{~m}^{2}$ of effective area in a flat sheet configuration. $\mathrm{A} \mathrm{NaCl}$ solution $(2 \mathrm{~L})$ was fed into the $\mathrm{RO}$ module in a recycle mode at a flow rate of $7.5 \mathrm{~L} / \mathrm{min}$. The experimental set-up is detailed in. ${ }^{4}$ The salt concentrations in the samples were determined using an ion analyzer (IA-300, DKK-TOA Corp., Tokyo, Japan). The water and salt permeance were recorded from the mass flow rates, normalized to the membrane area and applied pressure. ${ }^{4}$

\section{Results and discussion}

\section{Morphologies of thin-film composites}

The membrane cross-sections were examined using FESEM, as shown in Figure 1. Three layers were visible but the top PA layer was very thin. The total composite thickness was $154 \pm 10 \mu \mathrm{m}$ for AG 
and $178 \pm 1 \mu \mathrm{m}$ for $\mathrm{AK}$. The non-woven layer was about $93 \mu \mathrm{m}$ thick. The intermediate layer (made of PSf) accounted for $65 \pm 8 \mu \mathrm{m}$ for $\mathrm{AG}$ and $67 \pm 5 \mu \mathrm{m}$ for AK. This intermediate layer is micro-porous (Figure 2 ). The PA top layer was only a few hundred nanometers thick, with ripple morphology on the surface (Figure 2).

\section{Chemical structure}

The ATR-FTIR spectra of the RO membranes' PA layers are shown in Figure 3 (A). Typical amide I and amide II were visible, along with an aromatic ring structure. Figure 1(B) shows the enlarged view on $2700-3700 \mathrm{~cm}^{-1}$ range. The AK sample had a stronger $\mathrm{OH}$ group vibration peak than $\mathrm{AG}$.

The XPS spectra of these membranes are shown in Figure 4. The carbon, oxygen, and nitrogen contents were extracted and the results are summarized in Table 1. Using the previously proposed equation ${ }^{5,6}$ to calculate the cross-linking density ( $\mathrm{X}$ in Figure 5) from the XPS data, one could obtained that AG had a higher cross-linking density than $\mathrm{AK}(0.675$ vs. 0.225$)$. The $\mathrm{C} 1 \mathrm{~s}$ peak deconvolution results (Figure 6) also revealed that $\mathrm{AK}$ had more $\mathrm{COOH}$ functional groups, with less degree of cross-linking density than AG.

\section{Doppler broadening positron annihilation spectrosco- py}

The Doppler broadening positron annihilation spectra of the composites are shown in Figure 7. The AK sample had higher S parameters than $\mathrm{AG}$ at the low incident energy range $(0-4 \mathrm{keV})$, which corresponds to the PA top layer. ${ }^{7,8}$ This implies that the AK sample had higher free volume in the PA constituent. ${ }^{9}$ In the same energy range, the AK sample showed higher R parameter data than AG, implying that its pore size was larger ${ }^{10}$ and accounted for the higher free volume in AK.

\section{Salty water desalination performance}

The membranes were used for $1.5 \% \mathrm{NaCl}$ desalination and the results are summarized in Table 2 . The AG sample resulted in a lower water flux than AK (2.11 vs. $\left.3.04 \times 10^{-4} \mathrm{~m} / \mathrm{s}\right)$. This is in line with the Doppler broadening positron annihilation spectra: AK had higher free volume and water permeation rate than AG. The highly crosslinked AG sample has a dense structure that rejects salts molecules, rendering slightly higher $\mathrm{NaCl}$ rejection (98 vs. $97 \%$ ).

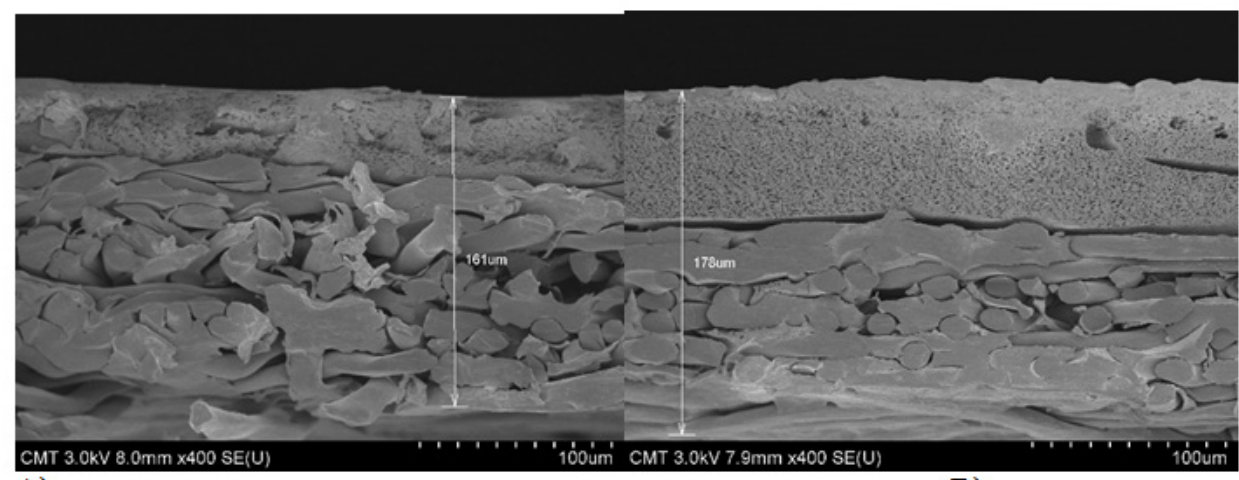

A)

B)

Figure I Scanning electron micrographs of cross-sectional views of AG (left) and AK (right) thin film composites. The composites consist of PA top layer, PSf intermediate layer, and non-woven substrate.

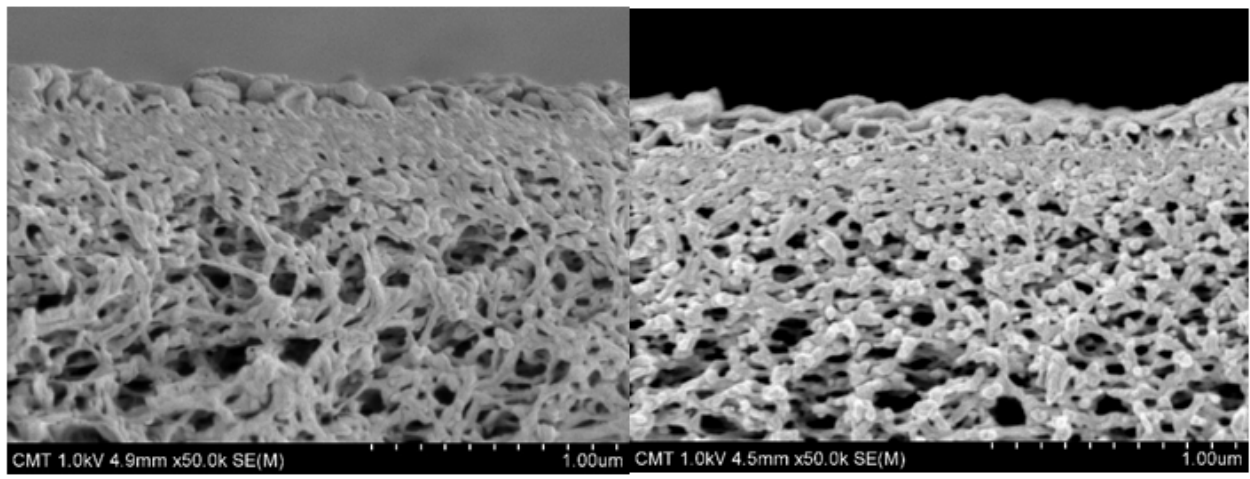

Figure 2 Scanning electron micrographs of cross-sectional views of PA/PSf portions on AG (left) and AK (right) composites.

Table I XPS results on RO membrane PA payers

\begin{tabular}{lcccccc}
\hline Membrane & C (\%) & O (\%) & N (\%) & O/N & Crosslinked & Linear \\
\hline AG & 78.5 & 11.8 & 9.6 & 1.23 & $0.60-0.75$ & $0.25-0.40$ \\
AK & 73.2 & 16.9 & 9.9 & 1.71 & $0.18-0.27$ & $0.73-0.82$ \\
\hline
\end{tabular}



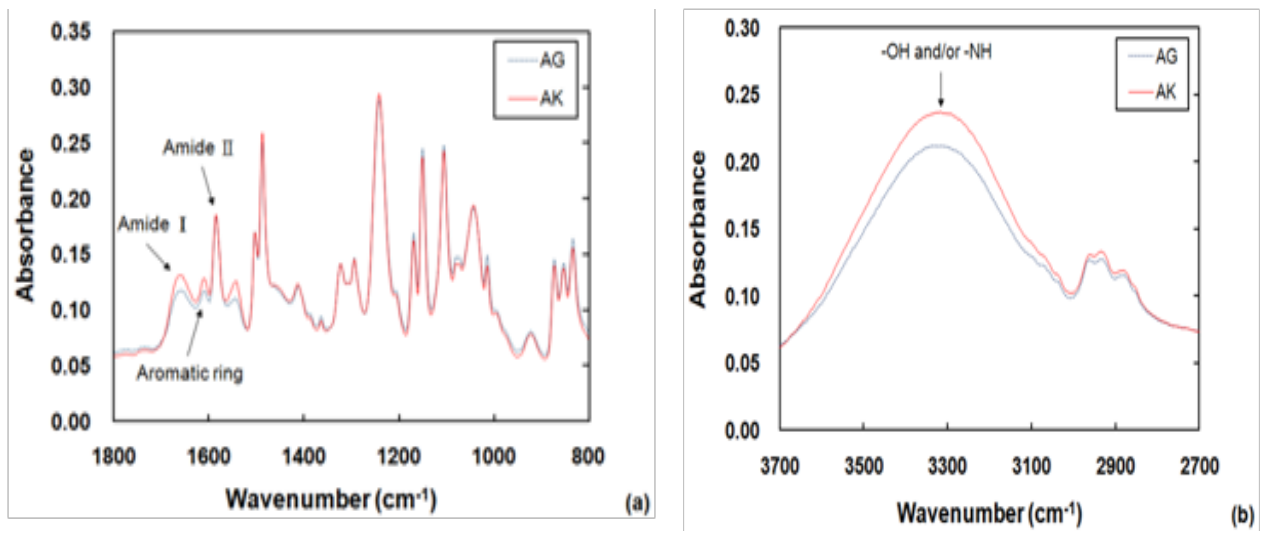

Figure 3 ATR-FTIR spectra of PA layers of RO membranes (A), with enlarged view on $2700-3700 \mathrm{~cm}-I$ range (B).
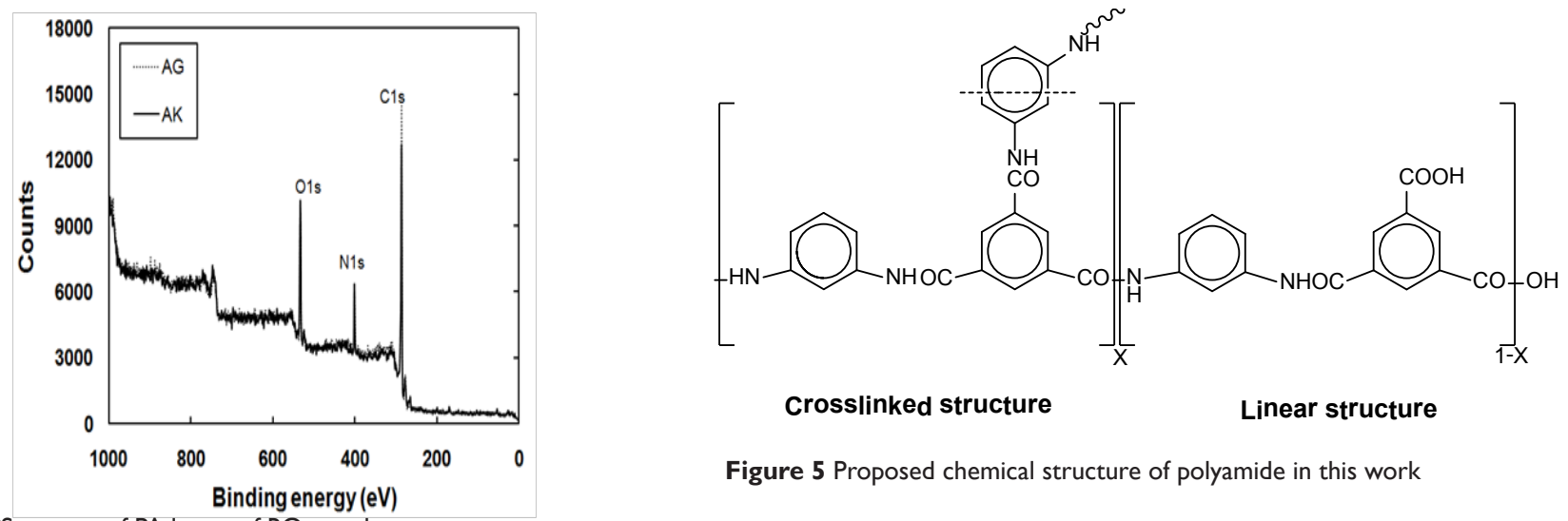

Crosslinked structure

Linear structure

Figure 5 Proposed chemical structure of polyamide in this work

Figure 4 XPS spectra of PA layers of RO membranes.
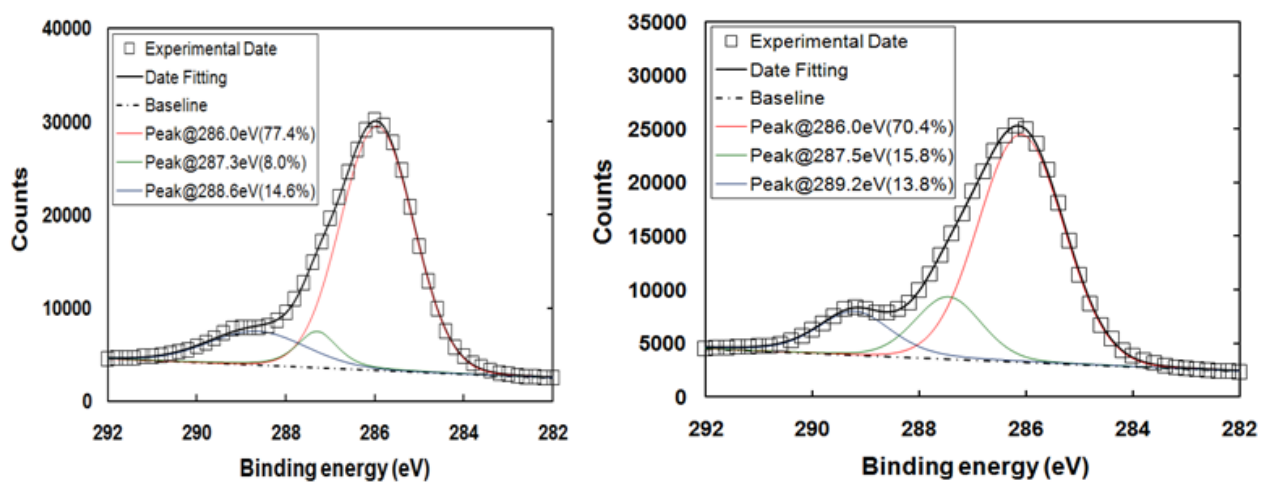

Figure $6 \mathrm{Cls}$ peak deconvolution of AG (left) and AK (right) membranes.
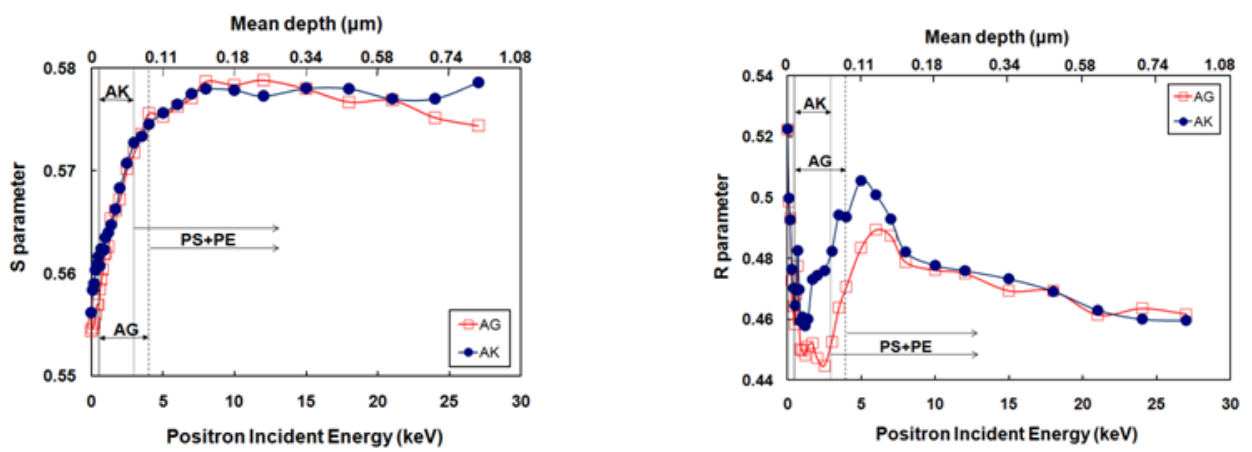

Figure $7 \mathrm{~S}$ parameters (top) and R parameters (bottom) for PA layers of membranes. 
Table 2 Salt permeability, water flux, salt rejection and water recovery through RO membranes

\begin{tabular}{lllll}
\hline Membrane & $J_{\mathrm{NaCl}}\left(10^{-3} \mathrm{~kg} / \mathrm{m}^{2} \mathbf{s}\right)$ & $J_{\text {water }}\left(10^{-4} \mathrm{~m}^{3} / \mathrm{m}^{2} \mathrm{~s}\right) \mathbf{b}$ & Rej. $(\%) \mathbf{b}$ & Recovery (\%) \\
\hline AG & 3.88 & 2.11 & 98.16 & 2.3 \\
AK & 8.15 & 3.04 & 97.32 & 3.3 \\
\hline
\end{tabular}

\section{Conclusion}

Two commercial polyamide (PA) thin film composites with different PA cross-linking densities were examined for morphology, chemical structure, Doppler broadening positron annihilation spectroscopy, and salt desalination performance. The highly crosslinked AG sample resulted in a higher salt rejection but slightly lower water permeance. Meanwhile, the highly cross-linked sample showed a smaller S parameter than the loosely cross-linked one. The results of the polymer cross-linking structure, salt rejection behavior, and Doppler broadening annihilation spectra are highly correlated to each other.

\section{Acknowledgements}

The financial support from the Ministry of Science and Technology of Taiwan (MOST 103-2221-E-182-064-MY3) is highly acknowledged.

\section{Conflict of interest}

The authors claim no financial interest or any conflict of interest.

\section{References}

1. Sharma VK, Singh PS, Gautam S, et al. Dynamics of water sorbed in reverse osmosis polyamide membrane. J Membr Sci. 2009;326(2):667671.

2. Huang SH, Lin WL, Liaw DJ, et al. Characterization, transport and sorption properties of poly(thiol ester amide) thin-film composite pervaporation membranes. J Membr Sci. 2008;322(11):139-145.
3. Cheng LH, Fu YJ, Liao KS, et al. A high-permeance supported carbon molecular sieve membrane fabricated by plasma-enhanced chemical vapor deposition followed by carbonization for $\mathrm{CO}_{2}$ capture. J Membr Sci. 2014;460:1-8

4. Hung LY, Lue SJ, You JH. Mass-transfer modeling of reverse-osmosis performance on $0.5-2 \%$ salty water. Desalination. 2011;265(1-3):67-73.

5. Tang CY, Kwon YN, Leckie JO. Probing the nano- and micro-scales of reverse osmosis membranes-A comprehensive characterization of physiochemical properties of uncoated and coated membranes by XPS, TEM, ATR-FTIR, and streaming potential measurements. J Membr Sci. 2007;287(1):146-156.

6. Koo J, Petersen RJ, Cadotte JE. ESCA characterization of chlorine-damaged polyamide reverse osmosis membrane. Polym Preprints. 1986;27(2):391-392.

7. Jean $\mathrm{YC}$, Chen $\mathrm{H}$, Zhang $\mathrm{S}$, et al. Characterizing free volumes and layer structures in polymeric membranes using slow positron annihilation spectroscopy. J Phys Conf Ser. 2011;262(1):012027.

8. Tung KL, Jean YC, Nanda D, et al. Characterization of multilayer nanofiltration membranes using positron annihilation spectroscopy. J Membr Sci. 2009;343(1-2):147-156.

9. Hung WS, Liang JH, Lecaros RLG, et al. Effect of free volume and formation mechanisms of polyamide layers on nanofiltration membrane. Sep Purif Technol. 2017;187:443-452.

10. Cheng LH, Fu YJ, Liao KS, et al. A high-permeance supported carbon molecular sieve membrane fabricated by plasma-enhanced chemical vapor deposition followed by carbonization for $\mathrm{CO}_{2}$ capture. J Membr Sci. 2014;460:1-8 